\title{
Design, Synthesis, and Spectroscopic Study of 7-Azaindolyl Hydrazones with Anti-Breast Cancer Activity
}

Sakharam B. Dongare, ${ }^{1}$ Babasaheb. P. Bandgar, ${ }^{1}$ Pravin S. Bhale, ${ }^{1}$ Sadanand N. Shringare, ${ }^{1}$ Hemant V. Chavan ${ }^{1,2, *}$

\footnotetext{
1 Medicinal Chemistry Research Laboratory, School of Chemical Sciences, Solapur University Solapur, Maharashtra, India-413255

2 Department of Chemistry, A. S. P. College, Devrukh, Dist: Ratnagiri (Affiliated to University of Mumbai), Maharashtra, India-415804

* Corresponding author's e-mail address: hemantchavan.sus@rediffmail.com
}

RECEIVED: September 18, 2018 * REVISED: December 10, 2018 * ACCEPTED: December 11, 2018

\begin{abstract}
A series of 7-azaindolyl hydrazones were prepared by reacting of hydrazides of 7-azaindole-3-acetic acids with aromatic aldehydes and $\mathrm{N}$-substituted indolyl-3-carboxyaldehydes. Structure of all the synthesized compounds were satisfactorily correlated by IR, ${ }^{1 H} \mathrm{NMR},{ }^{13} \mathrm{C}$ NMR and mass spectroscopic evidences. The synthesized compounds were evaluated for their possible anticancer potential against MCF-7 induced breast carcinoma. It is worth mentioning that most of the compounds were considerably active against MCF-7 cell line with $\mathrm{G} \mathrm{s}_{50}$ values ranging from 22.3-81.0 $\mathrm{MM}$. The hydrazones of $\mathrm{N}$-1-substituted indole-3-carboxyaldehydes $9 \mathrm{f}, 9 \mathrm{~g}, 9 \mathrm{~h}, 9 \mathrm{c}$, and $9 \mathrm{j}$ were active against MCF-7 cell line with $\mathrm{GI}_{50}$ values less than $40 \mu \mathrm{M}\left(\mathrm{G} \mathrm{I}_{50}=22.3\right.$ and $24.9,29.6,30.2$ and $37.8 \mu \mathrm{M}$ respectively) with moderate $\mathrm{TGI}$ values $(\mathrm{TGI}=56.6,59.5$, 65.5, 70.7 and $94.6 \mu \mathrm{M}$ respectively). The active compounds were also screened against the normal Vero monkey cell line, which showed moderate selectivity against inhibition of cancer cells.
\end{abstract}

Keywords: 7-azaindole, hydrazone, breast carcinoma.

\section{INTRODUCTION}

NDOLE is the most active pharmacophoric nucleus and major constituent of number of bio-molecules viz indole-3-acetic acid (IAA), oncracin-1, indole 3-carbinol (I3C), tryptophan, serotonin and melatonin. ${ }^{[1]}$ It is also found in various natural compounds such as alkaloids. ${ }^{[2]}$ The substituted bis-indole derivatives like nortopsentin, coscinamide A-C, indibulin, rhopaladin, labradorin, tenidap and aplysinopsins exhibited various pharmacological properties such as anti-inflammatory, analgesic and antitumor. ${ }^{[3]}$ One of the preferred approaches during drug development is to synthesize analogues of the lead compound. In this regard indole can be replaced with azaindole where the main core would be replaced with bioisosteric conceptual atom and to evaluate the effect on activity. This approach may enhance the biological activity with reducing side effects. Among the various bioisosters of azaindole, ${ }^{[4]} 7$-azaindole has received a great deal of attention due to wide variety of biological activities (Figure 1). ${ }^{[5,6]}$ Similarly, the functional framework of hydrazide / hydrazone (-CO-NH-N=CH-) has applications in building heterocyles ${ }^{[7]}$ with potential anti-inflammatory, antimalarial, anticonvulsant, anti-tuberculosis, antitumor, and antimicrobial activities. ${ }^{[8]}$ Apart from biological importance of hydrazine core, these derivatives

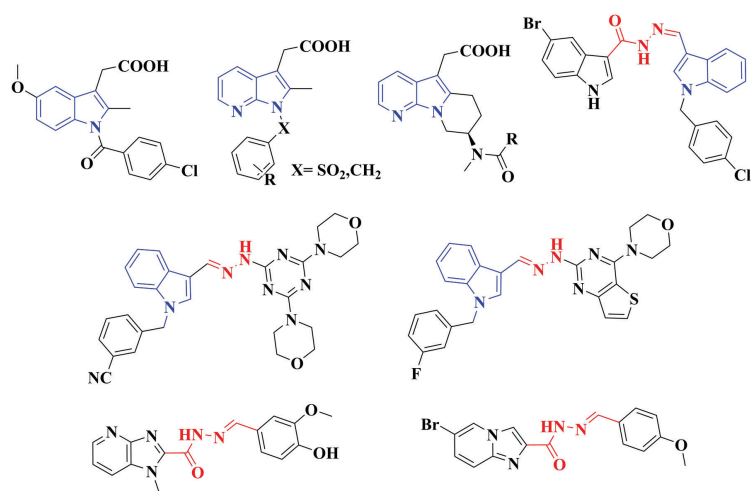

Figure 1. Bioactive compounds having hydrazide, hydrazone core with indole or other $\mathrm{N}$-heterocycles. 
have been studied and applied in supramolecular chemistry, metal and covalent organic framework, dynamic combinatorial chemistry, dyes and pigments chemistry. ${ }^{[9]}$

In continuation of our studies in synthesizing various biologically active compounds ${ }^{[10]}$ and all the above mentioned facts guided us to design and synthesize novel 7-azaindolyl hydrazones in order to evaluate their anticancer potential.

\section{EXPERIMENTAL}

\section{Materials and Methods}

All the chemicals used were of synthetic grade and procured from Sd-fine, Spectrochem and Aldrich chemicals. Completion of the reactions was monitored by thin layer chromatography (TLC) using E-Merck $0.25 \mathrm{~mm}$ silica gel plates using methanol: chloroform (1:9) as eluting medium. Visualization was accomplished with UV light and or iodine vapors. All the solvents were dried using appropriate drying agents before use. Melting points were determined by open end capillary method and are uncorrected. All the ${ }^{1} \mathrm{H}$ NMR spectra were recorded in DMSO- $\mathrm{d}_{6} / \mathrm{CDCl}_{3}$ and chemical shifts in ppm were reported on instrument Bruker AV- $400 \mathrm{MHz}$, for ${ }^{1} \mathrm{H} N M R$ and $75 \mathrm{MHz}$ for ${ }^{13} \mathrm{C}$ NMR relative to TMS as an internal standard. The IR spectra were recorded on Shimadzu FT-IR spectrophotometer by using $1 \%$ potassium bromide discs. The electron ionization mass spectra were recorded on Agilent 1100 series.

\section{Synthesis}

\section{PROCEDURE FOR PREPARATION OF (2-METHYL-1H- PYRROLO[2,3-B]PYRIDIN-3-YL)ACETIC ACID METHYL ESTER (4)}

The 2-methyl-7-azaindole-3-acetic acid (3) ${ }^{[11]}$ (10 mmol) were esterified in a classical manner with methanol and catalytic amount of con $\mathrm{H}_{2} \mathrm{SO}_{4}$ under reflux for $7 \mathrm{~h}$. After completion, the reaction mixture was cooled and solvent methanol was removed under reduced pressure. The residue was then poured onto crushed ice and extracted repeatedly with ethyl acetate. The ethyl acetate layer was washed with saturated sodium bicarbonate solution followed by water. The ethyl acetate layer was dried over sodium sulphate and distilled off under reduced pressure. The solid product obtained was filtered, washed with cold ethyl acetate and dried.

Yield: $82 \%$; m.p. $182-184{ }^{\circ} \mathrm{C}$; IR $\left(\mathrm{KBr}, \mathrm{cm}^{-1}\right): 3154$ (NH), $2952(\mathrm{CH}), 1730(\mathrm{C}=\mathrm{O}), 1626,1586,1558 ;{ }^{1} \mathrm{H} \mathrm{NMR}$ $\left(400 \mathrm{MHz}, \mathrm{CDCl}_{3}\right) \delta / \mathrm{ppm}: 2.55\left(\mathrm{~s}, 3 \mathrm{H}, \mathrm{CH}_{3}\right), 3.70(\mathrm{~s}, 3 \mathrm{H}$, $\left.\mathrm{CH}_{3}\right), 3.73(\mathrm{~s}, 2 \mathrm{H}), 7.07-7.10(\mathrm{~m}, 1 \mathrm{H}, \mathrm{ArH}), 7.88(\mathrm{~d}, J=4.0 \mathrm{~Hz}$, $1 \mathrm{H}, \mathrm{ArH}), 8.25(\mathrm{~d}, J=4.0 \mathrm{~Hz}, 1 \mathrm{H}, \mathrm{ArH}), 12.03(\mathrm{~s}, 1 \mathrm{H}, \mathrm{NH}),{ }^{13} \mathrm{C}$ $\mathrm{NMR}\left(75 \mathrm{MHz}, \mathrm{CDCl}_{3}\right): 21.83,30.11,51.97,102.41,115.39$, 121.56, 126.35, 134.29, 140.64, 148.32, 172.29; ESI-MS: $m / z 205.0(\mathrm{M}+1)$.

\section{PROCEDURE FOR PREPARATION OF (2-METHYL-1H- PYRROLO[2,3-B]PYRIDIN-3-YL)ACETIC ACID HYDRAZIDE (5)}

A solution of hydrazine hydrate ( $15 \mathrm{~mL}, 99 \%$ ) was added to a solution of methyl ester of 2-methyl-7-azaindole-3-acetic acid $4(10 \mathrm{mmol})$ in methanol $(25 \mathrm{~mL})$. The reaction mixture was refluxed for $5 \mathrm{~h}$. At the end of reaction monitored by $\mathrm{TLC}$, the reaction mixture was evaporated under reduced pressure to $1 / 4$ volume and by cooling the white crystalline pure product was obtained.

Yield: 85 \%; m.p. $192-194{ }^{\circ} \mathrm{C}$; IR $\left(\mathrm{KBr}, \mathrm{cm}^{-1}\right)$ : 3155 , $2952(\mathrm{CH}), 1626$ (C=O), 1600 (C=C), 1196, 1167, 993, 796, 769, 664, 652; ${ }^{1} \mathrm{H}$ NMR (400 MHz, DMSO-d 6 ) $\delta /$ ppm: 2.35 $\left(\mathrm{s}, 3 \mathrm{H}, \mathrm{CH}_{3}\right), 3.38\left(\mathrm{~s}, 2 \mathrm{H}, \mathrm{CH}_{2}\right), 4.17\left(\mathrm{~s}, 2 \mathrm{H}, \mathrm{NH}_{2}\right), 6.95$ (dd, $J=$ 6.8 and $4.0 \mathrm{~Hz}, 1 \mathrm{H}, \mathrm{ArH}), 7.85(\mathrm{~d}, J=8.0 \mathrm{~Hz}, 1 \mathrm{H}, \mathrm{ArH}), 8.06$ (d, J = 5.2 Hz, 1H, ArH), $9.13(\mathrm{~s}, 1 \mathrm{H}, \mathrm{NH}), 11.29$ (s, 1H, Indole$\mathrm{NH})$; ESI-MS: m/z 205.1 (M+1).

\section{GENERAL PROCEDURE FOR PREPARATION OF HYDRAZONE DERIVATIVES (8a-I)}

A mixture of (2-methyl-1H-pyrrolo[2,3-b]pyridin-3-yl)-acetic acid hydrazide $5(1.0 \mathrm{mmol})$ and substituted aromatic benzaldehyde $6 \mathrm{a}-\mathrm{I}(1.0 \mathrm{mmol})$ in $10 \mathrm{~mL}$ of ethanol and few drops of glacial acetic acid was stirred for 3-4 $\mathrm{h}$ at room temperature. A solid was separated out within 1520 minutes and the stirring was continued for $3-4 \mathrm{~h}$ to complete the reaction. The reaction progress was monitored by TLC (chloroform / methanol). After completion of the reaction, the product was collected with vacuum filtration and washed with cold ethanol to give off white crystals of the desired pure product.

\section{$N^{\prime}$-(2,4-Dichlorobenzylidene)-2-(2-methyl-1H-pyrrolo[2,3- b]pyridin-3-yl)acetohydrazide (8a)}

Yield: 91 \%; m.p. $272-274{ }^{\circ} \mathrm{C}$; IR $\left(\mathrm{KBr}, \mathrm{cm}^{-1}\right)$ : 3155, 3064, 2944, 2763, 1667, 1542, 1473, 1408, 1348, 1295, 1165, $1143,1100,1313,907,822,737 ;{ }^{1} \mathrm{H}$ NMR (400 MHz, DMSO$\left.\mathrm{d}_{6}\right) \delta / \mathrm{ppm}: 2.36\left(\mathrm{~s}, 3 \mathrm{H}, \mathrm{CH}_{3}\right), 4.03\left(\mathrm{~s}, 2 \mathrm{H}, \mathrm{CH}_{2}\right), 6.95$ (dd, $J=$ 4.8 and $2.8 \mathrm{~Hz}, 1 \mathrm{H}, \mathrm{ArH}), 7.51(\mathrm{~d}, J=8.8 \mathrm{~Hz}, 1 \mathrm{H}, \mathrm{ArH}), 7.70$ $7.71(\mathrm{~m}, 1 \mathrm{H}, \mathrm{ArH}), 7.80$ (d, J = 7.6 Hz, 1H, ArH), 8.07-8.08 (m, $2 \mathrm{H}, \mathrm{ArH}), 8.34(\mathrm{~s}, 1 \mathrm{H}, \mathrm{N}=\mathrm{CH}), 11.32(\mathrm{~s}, 1 \mathrm{H}, \mathrm{NH}), 11.54(\mathrm{~s}, 1 \mathrm{H}$, CONH); ${ }^{13} \mathrm{C}$ NMR (75 MHz, DMSO- $\left.d_{6}\right): 11.87,28.27,103.20$, $115.27,121.14,126.05,128.39,129.77,131.08,134.17$, 134.52, 135.22, 138.43, 141.63, 148.24, 167.81, 173.15; ESI-MS: $m$ / z $361.1(\mathrm{M}+)$

\section{$N^{\prime}$-(3,4-Difluorobenzylidene)-2-(2-methyl-1H-pyrrolo[2,3- b]pyridin-3-yl)acetohydrazide (8b)}

Yield 86 \%; m.p. 239-241 ${ }^{\circ} \mathrm{C}$; IR $\left(\mathrm{KBr}, \mathrm{cm}^{-1}\right)$ : 3146, 3075 (NH), 2944, 2913, 1670, 1613, 1552, 1526, 1497, 1469, 1341, 1188,$828 ;{ }^{1} \mathrm{H}$ NMR $\left(400 \mathrm{MHz}, \mathrm{DMSO}-\mathrm{d}_{6}\right) \delta / \mathrm{ppm}: 2.36$ (s, $\left.3 \mathrm{H}, \mathrm{CH}_{3}\right), 4.03\left(\mathrm{~s}, 2 \mathrm{H}, \mathrm{CH}_{2}\right), 6.95(\mathrm{dd}, J=4.8$ and $2.8 \mathrm{~Hz}, 1 \mathrm{H}$, $\operatorname{ArH}), 7.51(\mathrm{~d}, J=8.8 \mathrm{~Hz}, 1 \mathrm{H}, \mathrm{ArH}), 7.70-7.72(\mathrm{~m}, 1 \mathrm{H}, \mathrm{ArH})$, 
$7.93(\mathrm{~d}, J=8.4 \mathrm{~Hz}, 1 \mathrm{H}, \mathrm{ArH}), 8.07-8.08(\mathrm{~m}, 2 \mathrm{H}, \mathrm{ArH}), 8.34$ (s, $1 \mathrm{H}, \mathrm{N}=\mathrm{CH}), 11.32(\mathrm{~s}, 1 \mathrm{H}, \mathrm{NH}), 11.54(\mathrm{~s}, 1 \mathrm{H}, \mathrm{CONH})$; ESI-MS: $\mathrm{m} / \mathrm{z} 328.11(\mathrm{M}+1)$.

\section{2-(2-Methyl-1H-pyrrolo[2,3-b]pyridin-3-yl)-N'-(3,4,5-} trimethoxybenzylidene)acetohydrazide (8c)

Yield $93 \%$; m.p. $259-261{ }^{\circ} \mathrm{C}$; IR $\left(\mathrm{KBr}, \mathrm{cm}^{-1}\right): 3197,3066$, 2987, 2940, 1669, 1579, 1499, 1465, 1368, 1156, 954, 806, 769,$664 ;{ }^{1} \mathrm{H}$ NMR (400 MHz, DMSO-d 6 ) $\delta /$ ppm: 2.39 (s, 3H, $\left.\left.\mathrm{CH}_{3}\right), 3.58\left(\mathrm{~s}, 2 \mathrm{H}, \mathrm{CH}_{2}\right), 3.70(\mathrm{~s}, 3 \mathrm{H} \mathrm{OCH})_{3}\right), 3.82(\mathrm{~s}, 6 \mathrm{H}, 2-$ $\left.\mathrm{OCH}_{3}\right), 6.91-6.93(\mathrm{~m}, 1 \mathrm{H}, \mathrm{ArH}), 6.95(\mathrm{~s}, 1 \mathrm{H}, \mathrm{ArH}), 7.02(\mathrm{~s}, 1 \mathrm{H}$, ArH), 7.87-7.91 (m, 1H, ArH), 8.05-8.08 (m, 1H, ArH), 8.17 $(\mathrm{s}, 1 \mathrm{H}, \mathrm{N}=\mathrm{CH}), 11.32(\mathrm{~s}, 1 \mathrm{H}, \mathrm{NH}), 11.46(\mathrm{~s}, 1 \mathrm{H}, \mathrm{CONH})$; ESIMS: $m$ / z $383.2(\mathrm{M}+1)$

\section{$N^{\prime}$-(Benzo[d][1,3]dioxol-5-yl-methylene)-2-(2-methyl-1H- pyrrolo[2,3-b]pyridin-3-yl)acetohydrazide (8d)}

Yield 90 \%; m.p. 235-237 ${ }^{\circ} \mathrm{C}$; IR $\left(\mathrm{KBr}, \mathrm{cm}^{-1}\right)$ : 3206, 3063, 2941, 2901, 1665, 1624, 1588, 1547, 1489, 1450, 1389, $1199,1185,1007,867,716,666$; ${ }^{1} \mathrm{H}$ NMR (400 MHz, DMSO$\left.\mathrm{d}_{6}\right) \delta / \mathrm{ppm}: 2.39\left(\mathrm{~s}, 3 \mathrm{H}, \mathrm{CH}_{3}\right), 3.98\left(\mathrm{~s}, 2 \mathrm{H}, \mathrm{CH}_{2}\right), 6.08(\mathrm{~s}, 2 \mathrm{H}$, $\left.\mathrm{OCH}_{2}\right), 6.95-6.98(\mathrm{~m}, 2 \mathrm{H}, \mathrm{ArH}), 7.11(\mathrm{~d}, J=8.0 \mathrm{~Hz}, 1 \mathrm{H}, \mathrm{ArH})$, 7.21-7.33 (m, $1 \mathrm{H}, \mathrm{ArH}), 7.82-7.90(\mathrm{~m}, 1 \mathrm{H}, \mathrm{ArH}), 8.04-8.07$ (m, $1 \mathrm{H}, \mathrm{ArH}), 8.15(\mathrm{~s}, 1 \mathrm{H}, \mathrm{N}=\mathrm{CH}), 11.19(\mathrm{~s}, 1 \mathrm{H}, \mathrm{NH}), 11.38$ (s, $1 \mathrm{H}, \mathrm{CONH})$; ESI-MS: $m$ / $z 337.2(\mathrm{M}+1)$.

\section{$N^{\prime}$-(2,4-Difluorobenzylidene)-2-(2-methyl-1H-pyrrolo[2,3- b]pyridin-3-yl)acetohydrazide (8e)}

Yield $86 \%$; m.p. $239-241^{\circ} \mathrm{C}$; IR $\left(\mathrm{KBr}, \mathrm{cm}^{-1}\right)$ : 3146, 3075 (NH), 2944, 2913, 1670, 1613, 1552, 1526, 1497, 1469, 1341 1188,$828 ;{ }^{1} \mathrm{H}$ NMR (400 MHz, DMSO-d 6 ) $\delta / \mathrm{ppm:} 2.36$ (s, $\left.3 \mathrm{H}, \mathrm{CH}_{3}\right), 4.03\left(\mathrm{~s}, 2 \mathrm{H}, \mathrm{CH}_{2}\right), 6.95$ (dd, $J=4.8$ and $2.8 \mathrm{~Hz}, 1 \mathrm{H}$, $\mathrm{ArH}), 7.51(\mathrm{~d}, J=8.8 \mathrm{~Hz}, 1 \mathrm{H}, \mathrm{ArH}), 7.70-7.72(\mathrm{~m}, 1 \mathrm{H}, \mathrm{ArH})$, $7.93(\mathrm{~d}, J=8.4 \mathrm{~Hz}, 1 \mathrm{H}, \mathrm{ArH}), 8.07-8.08(\mathrm{~m}, 2 \mathrm{H}, \mathrm{ArH}), 8.34(\mathrm{~s}$, $1 \mathrm{H}, \mathrm{N}=\mathrm{CH}), 11.32(\mathrm{~s}, 1 \mathrm{H}, \mathrm{NH}), 11.54(\mathrm{~s}, 1 \mathrm{H}, \mathrm{CONH}) ; \mathrm{ESI}-\mathrm{MS}$ : $m / z 328.11(\mathrm{M}+1)$.

\section{2-(2-Methyl-1H-pyrrolo[2,3-b]pyridin-3-yl)-N'-(3- nitrobenzylidene)acetohydrazide (8f)}

Yield 85 \%; m.p.238-240 ${ }^{\circ} \mathrm{C}$; IR $\left(\mathrm{KBr}, \mathrm{cm}^{-1}\right)$ : 3154, 3079, 2953, 1673, 1560, 1531, 1471, 1439, 1588, 1347, 1293, 1144, 954, 736; ${ }^{1} \mathrm{H}$ NMR (400 MHz, DMSO-d 6 ) $\delta$ / ppm: 2.40 $\left(\mathrm{s}, 3 \mathrm{H}, \mathrm{CH}_{3}\right), 4.04\left(\mathrm{~s}, 2 \mathrm{H}, \mathrm{CH}_{2}\right), 6.92-6.93(\mathrm{~m}, 1 \mathrm{H}, \mathrm{ArH}), 7.72$ $7.74(\mathrm{~m}, 1 \mathrm{H}, \mathrm{ArH}), 7.83-7.85(\mathrm{~m}, 1 \mathrm{H}, \mathrm{ArH}), 8.06-8.16(\mathrm{~m}$, $3 \mathrm{H}, \mathrm{ArH}), 8.37(\mathrm{~s}, 1 \mathrm{H}, \mathrm{N}=\mathrm{CH}), 8.50-8.54(\mathrm{~m}, 1 \mathrm{H}, \mathrm{ArH}), 11.37$ (s, 1H, NH), 11.55 (s, 1H, CONH); ESI-MS: $m$ / z $338.2(\mathrm{M}+1)$.

\section{2-(2-Methyl-1H-pyrrolo[2,3-b]pyridin-3-yl)-N'-(2,4,6-} trimethoxybenzylidene)acetohydrazide $(8 \mathrm{~g})$

Yield 85 \%; m.p. $280-282{ }^{\circ} \mathrm{C}$; IR $\left(\mathrm{KBr}, \mathrm{cm}^{-1}\right)$ : 3199, 3060, 2997, 2940, 1667, 1578, 1497, 1462, 1368, 1156, 952, 806, 767,$664 ;{ }^{1} \mathrm{H}$ NMR (400 MHz, DMSO-d 6 ) $\delta / \mathrm{ppm}: 2.33(\mathrm{~s}, 3 \mathrm{H}$, $\left.\mathrm{CH}_{3}\right), 3.76\left(\mathrm{~s}, 3 \mathrm{H}, \mathrm{OCH}_{3}\right), 3.82\left(\mathrm{~s}, 6 \mathrm{H}, \mathrm{OCH}_{3}\right), 3.92\left(\mathrm{~s}, 2 \mathrm{H}, \mathrm{CH}_{2}\right)$, $6.30(\mathrm{~s}, 2 \mathrm{H}, \mathrm{ArH}), 6.89-6.92(\mathrm{~m}, 1 \mathrm{H}, \mathrm{ArH}), 7.89-7.90(\mathrm{~m}, 1 \mathrm{H}$, ArH), 8.03-8.04 (m, 1H, ArH), $8.15(\mathrm{~s}, 1 \mathrm{H}, \mathrm{N}=\mathrm{CH}), 10.91(\mathrm{~s}$, $1 \mathrm{H}, \mathrm{NH}), 11.27$ (s, 1H, CONH); ESI-MS: $m$ / z $383.2(\mathrm{M}+1)$

\section{N'-(3-Bromobenzylidene)-2-(2-methyl-1H-pyrrolo[2,3- b]pyridin-3-yl)acetohydrazide $(8 \mathrm{~h})$}

Yield 89 \%; m.p. $290-292{ }^{\circ} \mathrm{C}$; IR $\left(\mathrm{KBr}, \mathrm{cm}^{-1}\right)$ : 3156, 3062, 2952, 1672, 1588, 1558, 1468, 1443, 1343, 1270, 1068, 887, 703, 682; ${ }^{1} \mathrm{H}$ NMR (400 MHz, DMSO-d 6 ) $\delta /$ ppm: 2.39 (s, 3H, $\left.\mathrm{CH}_{3}\right), 4.01\left(\mathrm{~s}, 2 \mathrm{H}, \mathrm{CH}_{2}\right), 6.92-6.95(\mathrm{~m}, 1 \mathrm{H}, \mathrm{ArH}), 7.37-7.42$ (m, 1H, ArH), 7.59-7.61 (m, 1H, ArH), 7.65-7.70 (m, 1H, ArH), 7.82-7.87 (m, 1H, ArH), $7.96(\mathrm{~s}, 1 \mathrm{H}, \mathrm{ArH}), 8.05-8.08$ $(\mathrm{m}, 1 \mathrm{H}, \mathrm{ArH}), 8.20(\mathrm{~s}, 1 \mathrm{H}, \mathrm{N}=\mathrm{CH}), 11.41(\mathrm{~s}, 1 \mathrm{H}, \mathrm{NH}), 11.63(\mathrm{~s}$, $1 \mathrm{H}, \mathrm{CONH})$; ESI-MS: $m$ / z $371.1(\mathrm{M}+)\left({ }^{79} \mathrm{Br}\right)$.

\section{N'-(4-Hydroxybenzylidene)-2-(2-methyl-1H-pyrrolo[2,3- b]pyridin-3-yl)acetohydrazide (8i)}

Yield 92 \%; m.p. $270-272{ }^{\circ} \mathrm{C}$; IR $\left(\mathrm{KBr}, \mathrm{cm}^{-1}\right)$ : 3649, 3195, 3047, 2938, 2902, 1671, 1572, 1441, 1417, 1286, 1183, 902, 736; ${ }^{1} \mathrm{H}$ NMR (400 MHz, DMSO-d 6 ) $\delta / p p m: 2.41$ (s, 3H, $\left.\mathrm{CH}_{3}\right), 3.96\left(\mathrm{~s}, 2 \mathrm{H}, \mathrm{CH}_{2}\right), 6.70-6.75(\mathrm{~m}, 1 \mathrm{H}, \mathrm{ArH}), 6.95-6.98$ $(\mathrm{m}, 1 \mathrm{H}, \mathrm{ArH}), 7.31(\mathrm{~s}, 1 \mathrm{H}, \mathrm{ArH}), 7.76-7.82(\mathrm{~m}, 1 \mathrm{H}, \mathrm{ArH})$, 8.03-8.07 (m, 3H, ArH), $8.13(\mathrm{~s}, 1 \mathrm{H}, \mathrm{N}=\mathrm{CH}), 9.43(\mathrm{~s}, 1 \mathrm{H}$, $\mathrm{OH}), 11.23(\mathrm{~s}, 1 \mathrm{H},-\mathrm{NH}), 11.47(\mathrm{~s}, 1 \mathrm{H}, \mathrm{CONH}) ; \mathrm{ESI}-\mathrm{MS}: \mathrm{m} / \mathrm{z}$ $309.2(\mathrm{M}+1)$

N'-(3-Fluoro-4-methoxybenzylidene)-2-(2-methyl-1Hpyrrolo[2,3-b]pyridin-3-yl)acetohydrazide (8j)

Yield $86 \%$; m.p. $210-212{ }^{\circ} \mathrm{C}$; IR $\left(\mathrm{KBr}, \mathrm{cm}^{-1}\right)$ : 3649, 3246, $3156,3059,2994,2943,1667,1577,1549,1470,1440$, $1189,1020,871 ;{ }^{1} \mathrm{H}$ NMR (400 MHz, DMSO-d 6 ) $\delta / \mathrm{ppm}$ : $2.39\left(\mathrm{~s}, 3 \mathrm{H}, \mathrm{CH}_{3}\right), 3.88\left(\mathrm{~s}, 3 \mathrm{H}, \mathrm{OCH}_{3}\right), 3.99\left(\mathrm{~s}, 2 \mathrm{H}, \mathrm{CH}_{2}\right), 6.91-$ $6.94(\mathrm{~m}, 1 \mathrm{H}, \mathrm{ArH}), 7.20-7.24(\mathrm{~m}, 1 \mathrm{H}, \mathrm{ArH}), 7.46(\mathrm{~d}, J=8.0 \mathrm{~Hz}$, $1 \mathrm{H}, \mathrm{ArH}), 7.60$ (d, $J=12.0 \mathrm{~Hz}, 1 \mathrm{H}, \mathrm{ArH}), 7.83(\mathrm{~d}, J=7.6 \mathrm{~Hz}, 1 \mathrm{H}$, $\mathrm{ArH}), 7.92(\mathrm{~s}, 1 \mathrm{H}, \mathrm{N}=\mathrm{CH}), 8.04-8.07(\mathrm{~m}, 1 \mathrm{H}, \mathrm{ArH}), 11.26(\mathrm{~s}, 1 \mathrm{H}$, $\mathrm{NH}), 11.45$ (s, 1H, CONH); ESI-MS: $m$ / z $341.2(\mathrm{M}+1)$.

\section{$N^{\prime}$-(4-Hydroxy-3-methoxybenzylidene)-2-(2-methyl-1H- pyrrolo[2,3-b]pyridin-3-yl)acetohydrazide (8k)}

Yield 90 \%; m.p. 230-232 ${ }^{\circ} \mathrm{C}$; IR ( $\left.\mathrm{KBr}, \mathrm{cm}^{-1}\right)$ : 3649, 3222, $3201,3047,2836,1664,1543,1514,1455,1430,1388$, $1144,1075,955,803 ;{ }^{1} \mathrm{H}$ NMR (400 MHz, DMSO-d 6 ) $\delta / \mathrm{ppm}$ : $2.39\left(\mathrm{~s}, 3 \mathrm{H}, \mathrm{CH}_{3}\right), 3.81\left(\mathrm{~s}, 3 \mathrm{H}, \mathrm{OCH}_{3}\right), 3.98\left(\mathrm{~s}, 2 \mathrm{H}, \mathrm{CH}_{2}\right), 6.79$ $6.83(\mathrm{~m}, 1 \mathrm{H}, \mathrm{ArH}), 6.91-6.94(\mathrm{~m}, 1 \mathrm{H}, \mathrm{ArH}), 6.96-6.99(\mathrm{~m}, 1 \mathrm{H}$, ArH), $7.31(\mathrm{~s}, 1 \mathrm{H}, \mathrm{ArH}), 7.82-7.88(\mathrm{~m}, 1 \mathrm{H}, \mathrm{ArH}), 8.04-8.07(\mathrm{~m}$, $1 \mathrm{H}, \mathrm{ArH}), 8.12(\mathrm{~s}, 1 \mathrm{H}, \mathrm{N}=\mathrm{CH}), 9.49(\mathrm{~s}, 1 \mathrm{H}, \mathrm{OH}), 11.26(\mathrm{~s}, 1 \mathrm{H}$, $\mathrm{NH}), 11.45$ (s, 1H, CONH); ESI-MS: m/z $339.2(\mathrm{M}+1)$.

\section{$N^{\prime}$-(4-Cyanobenzylidene)-2-(2-methyl-1H-pyrrolo[2,3- b]pyridin-3-yl) acetohydrazide (8I)}

Yield 88 \%; m.p. $195-197^{\circ} \mathrm{C}$; IR ( $\left.\mathrm{KBr}, \mathrm{cm}^{-1}\right)$ : 3650, 3242, $3208,3156,3050,2843,2764,2227,1670,1505,1460$, $1392,1361,1253,1167,1110,1015,974,932,739 ;{ }^{1} \mathrm{H}$ NMR 
(400 MHz, DMSO- $\left.\mathrm{d}_{6}\right) \delta / \mathrm{ppm}: 2.43\left(\mathrm{~s}, 3 \mathrm{H}, \mathrm{CH}_{3}\right), 3.98(\mathrm{~s}, 2 \mathrm{H}$, $\left.\mathrm{CH}_{2}\right), 6.72-6.77(\mathrm{~m}, 1 \mathrm{H}, \mathrm{ArH}), 6.96-6.98(\mathrm{~m}, 1 \mathrm{H}, \mathrm{ArH}), 7.76$ $(\mathrm{d}, J=8 \mathrm{~Hz}, 2 \mathrm{H}), 8.03-8.09(\mathrm{~m}, 3 \mathrm{H}), 8.13(\mathrm{~s}, 1 \mathrm{H}, \mathrm{N}=\mathrm{CH}), 11.26$ (s, 1H, NH), 11.49 (s, 1H, CONH); ESI-MS: $m$ / z $318.2(\mathrm{M}+1)$.

\section{GENERAL PROCEDURE FOR PREPARATION OF HYDRAZONE DERIVATIVES (9a-j)}

A mixture of 2-(2-methyl-1H-pyrrolo[2,3-b]pyridine-3yl)acetohydrazide $5(1.0 \mathrm{mmol})$ and $\mathrm{N}-1$ substituted-indole3-carbaldehyde $7 \mathrm{a}-\mathrm{j}(1.0 \mathrm{mmol})$ in $10 \mathrm{ml}$ ethanol and few drops of glacial acetic acid was refluxed for 3-4 $\mathrm{h}$ to complete the reaction. The reaction progress was monitored by TLC (chloroform/methanol). After completion of the reaction, the mixture was cooled to room temperature and collected the product with filtration and washed with cold ethanol to give white crystals of the desired pure product.

N'-((1-(4-Chlorobenzyl)-1H-indol-3-yl)-methylene)-2-(2methyl-1H-pyrrolo[2,3-b]pyridin-3-yl)acetohydrazide (9a) Yield 81 \%; m.p. 192-194 ${ }^{\circ} \mathrm{C}$; IR (KBr, cm$\left.{ }^{-1}\right)$ : 3154, 3067, 2941, 2842, 1668, 1583, 1545, 1491, 1460, 1235, 1141, 762; ${ }^{1} \mathrm{H}$ NMR (400 MHz, DMSO-d 6 ) $\delta /$ ppm: $2.33\left(\mathrm{~s}, 3 \mathrm{H}, \mathrm{CH}_{3}\right)$, $4.07\left(\mathrm{~s}, 2 \mathrm{H}, \mathrm{CH}_{2}\right), 5.46(\mathrm{~s}, 2 \mathrm{H}), 6.87-6.90(\mathrm{~m}, 1 \mathrm{H}), 7.10-7.29$ $(\mathrm{m}, 4 \mathrm{H}), 7.37-7.40(\mathrm{~m}, 1 \mathrm{H}), 7.47-7.52(\mathrm{~m}, 1 \mathrm{H}), 7.81(\mathrm{~d}, J=$ $7.2 \mathrm{~Hz}, 1 \mathrm{H}), 7.95-7.98(\mathrm{~m}, 1 \mathrm{H}), 7.98(\mathrm{~s}, 1 \mathrm{H}), 8.05(\mathrm{~d}, J=$ $4.0 \mathrm{~Hz}, 1 \mathrm{H}), 8.17-8.20(\mathrm{~m}, 1 \mathrm{H}), 8.22(\mathrm{~s}, 1 \mathrm{H}), 11.06(\mathrm{~s}, 1 \mathrm{H}$, $\mathrm{NH}), 11.32(\mathrm{~s}, 1 \mathrm{H}, \mathrm{CONH})$; ESI-MS: $m$ / z 456.29 (M+).

$N^{\prime}-((1-(4-F l u o r o b e n z y l)-1 H-i n d o l-3-y l)-m e t h y l e n e)-2-(2-$ methyl-1H-pyrrolo[2,3-b]pyridin-3-yl) acetohydrazide (9b) Yield $83 \%$; m.p. $210-212{ }^{\circ} \mathrm{C}$; IR $\left(\mathrm{KBr}, \mathrm{cm}^{-1}\right)$ : 3158, 3054, 2939, 2843, 1640, 1574, 1562, 1445, 1418, 1292, 1156, 747; ${ }^{1} \mathrm{H}$ NMR (400 MHz, DMSO-d 6 ) $\delta / \mathrm{ppm}: 2.37\left(\mathrm{~s}, 3 \mathrm{H}, \mathrm{CH}_{3}\right)$, $4.06\left(\mathrm{~s}, 2 \mathrm{H}, \mathrm{CH}_{2}\right), 5.44\left(\mathrm{~s}, 2 \mathrm{H}, \mathrm{N}-\mathrm{CH}_{2}\right), 6.87-6.90(\mathrm{~m}, 1 \mathrm{H}$, ArH), 7.14-7.21 (m, 3H, ArH), 7.31-7.33 (m, 2H, ArH), 7.55 (d, $J=8.0 \mathrm{~Hz}, 1 \mathrm{H}, \mathrm{ArH}), 7.81(\mathrm{~d}, J=7.2 \mathrm{~Hz}, 1 \mathrm{H}, \mathrm{ArH}), 7.95-$ $7.98(\mathrm{~m}, 1 \mathrm{H}, \mathrm{ArH}), 7.98(\mathrm{~s}, 1 \mathrm{H}, \mathrm{ArH}), 8.05$ (d, J = 4.0 Hz, 1H, $\mathrm{ArH}), 8.17-8.19(\mathrm{~m}, 1 \mathrm{H}, \mathrm{ArH}), 8.22(\mathrm{~s}, 1 \mathrm{H}, \mathrm{N}=\mathrm{CH}), 11.10(\mathrm{~s}$, $1 \mathrm{H}, \mathrm{NH}), 11.32$ (s, 1H, CONH); ESI-MS: $m$ / z $440.28(\mathrm{M}+1)$.

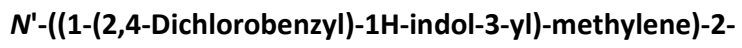
(2-methyl-1H-pyrrolo[2,3-b]pyridin-3-yl)acetohydrazide (9c)

Yield 84 \%; m.p. 201-203 ${ }^{\circ} \mathrm{C}$; IR $\left(\mathrm{KBr}, \mathrm{cm}^{-1}\right)$ : 3155, 3064, 2944, 1667, 1587, 1558, 1473, 1441, 1371, 1261, 1054, 868, 809; ${ }^{1} \mathrm{H}$ NMR (400 MHz, DMSO- $\left.\mathrm{d}_{6}\right): \delta / \mathrm{ppm}=2.38(\mathrm{~s}, 3 \mathrm{H}$, $\left.\mathrm{CH}_{3}\right), 4.07\left(\mathrm{~s}, 2 \mathrm{H}, \mathrm{CH}_{2}\right), 5.54\left(\mathrm{~s}, 2 \mathrm{H}, \mathrm{N}-\mathrm{CH}_{2}\right), 6.76-6.80(\mathrm{~m}$, $1 \mathrm{H}, \mathrm{ArH}), 6.88-6.91(\mathrm{~m}, 1 \mathrm{H}, \mathrm{ArH}), 7.13-7.24(\mathrm{~m}, 2 \mathrm{H}, \mathrm{ArH})$, 7.34-7.37 (m, 1H, ArH), 7.41-7.47 (m, 1H, ArH), $7.71(\mathrm{~s}, 1 \mathrm{H}$, ArH), 7.82-7.92 (m, 2H, ArH), $8.05(\mathrm{~d}, J=4.0 \mathrm{~Hz}, 1 \mathrm{H}, \mathrm{ArH})$, $8.22(\mathrm{~s}, 1 \mathrm{H}, \mathrm{N}=\mathrm{CH}), 8.23-8.25(\mathrm{~m}, 1 \mathrm{H}, \mathrm{ArH}), 11.08(\mathrm{~s}, 1 \mathrm{H}$, $\mathrm{NH}), 11.36$ (s, 1H, CONH); ESI-MS: $m$ / z $490.26(\mathrm{M}+)$.
$N^{\prime}$-((1-(2,4-difluorobenzyl)-1H-indol-3-yl)-methylene)-2(2-methyl-1H-pyrrolo[2,3-b]pyridin-3-yl)acetohydrazide (9d)

Yield 85 \%; m.p. $225-227^{\circ} \mathrm{C}$; IR $\left(\mathrm{KBr}, \mathrm{cm}^{-1}\right)$ : 3246, 3158, 2993, 2765, 1670, 1615, 1506, 1409, 1373, 1293, 1253, 1167, 1140, 1090, 974, 851, 812, 739, 652; ${ }^{1} \mathrm{H}$ NMR (400 $\left.\mathrm{MHz}, \mathrm{DMSO}-\mathrm{d}_{6}\right) \delta$ / ppm: $2.37\left(\mathrm{~s}, 3 \mathrm{H}, \mathrm{CH}_{3}\right), 4.06\left(\mathrm{~s}, 2 \mathrm{H}, \mathrm{CH}_{2}\right)$, $5.49\left(\mathrm{~s}, 2 \mathrm{H}, \mathrm{N}-\mathrm{CH}_{2}\right), 6.87-6.90(\mathrm{~m}, 1 \mathrm{H}, \mathrm{ArH}), 7.06-7.13(\mathrm{~m}$, $1 \mathrm{H}, \mathrm{ArH}), 7.16-7.29(\mathrm{~m}, 3 \mathrm{H}, \mathrm{ArH}), 7.51-7.56(\mathrm{~m}, 1 \mathrm{H}, \mathrm{ArH})$, $7.81(\mathrm{~d}, J=7.6 \mathrm{~Hz}, 1 \mathrm{H}, \mathrm{ArH}), 7.87-7.91(\mathrm{~m}, 2 \mathrm{H}, \mathrm{ArH}), 8.02$ (d, $J=4.0 \mathrm{~Hz}, 1 \mathrm{H}, \mathrm{ArH}), 8.17-8.20(\mathrm{~m}, 1 \mathrm{H}, \mathrm{ArH}), 8.21(\mathrm{~s}, 1 \mathrm{H}$, $\mathrm{N}=\mathrm{CH}), 11.06$ (s, 1H, NH), 11.35 (s, 1H, CONH); ESI-MS: $m$ / z $458.29(\mathrm{M}+1)$.

$N^{\prime}-((1-(2,4-D i c h l o r o b e n z y l)-5-m e t h o x y-1 H-i n d o l-3-y l)-$ methylene)-2-(2-methyl-1H-pyrrolo[2,3-b]pyridin-3yl)acetohydrazide (9e)

Yield $81 \%$; m.p. $220-222{ }^{\circ} \mathrm{C}$; IR $\left(\mathrm{KBr}, \mathrm{cm}^{-1}\right)$ : 3155, 3068, 2942, 1667, 1541, 1505, 1471, 1255, 1230, 1165, 1046, 905, 851; ${ }^{1} \mathrm{H}$ NMR (400 MHz, DMSO-d 6 ) $\delta / p p m: 2.37$ (s, 3H, $\left.\mathrm{CH}_{3}\right), 3.66\left(\mathrm{~s}, 3 \mathrm{H}, \mathrm{OCH}_{3}\right), 4.08\left(\mathrm{~s}, 2 \mathrm{H}, \mathrm{CH}_{2}\right), 5.45(\mathrm{~s}, 2 \mathrm{H}, \mathrm{N}-$ $\left.\mathrm{CH}_{2}\right), 6.84-6.89(\mathrm{~m}, 2 \mathrm{H}, \mathrm{ArH}), 7.04-7.06(\mathrm{~m}, 1 \mathrm{H}, \mathrm{ArH}), 7.21-$ $7.30(\mathrm{~m}, 2 \mathrm{H}, \mathrm{ArH}), 7.45(\mathrm{~d}, J=8.8 \mathrm{~Hz}, 1 \mathrm{H}, \operatorname{ArH}), 7.73(\mathrm{~s}, 1 \mathrm{H}$, ArH), 7.79-7.85 (m, 2H, ArH), $8.04(\mathrm{~d}, J=4.0 \mathrm{~Hz}, 1 \mathrm{H}, \mathrm{ArH})$, $8.20(\mathrm{~s}, 1 \mathrm{H}, \mathrm{N}=\mathrm{CH}), 11.05(\mathrm{~s}, 1 \mathrm{H}, \mathrm{NH}), 11.32(\mathrm{~s}, 1 \mathrm{H}, \mathrm{CONH})$; ESI-MS: $m$ / z $520.26(\mathrm{M}+)$.

$N^{\prime}-((1-(2,4-D i f l u o r o b e n z y l)-5-m e t h o x y-1 H-i n d o l-3-y l)-$ methylene)-2-(2-methyl-1H-pyrrolo[2,3-b]pyridin-3yl)acetohydrazide (9f)

Yield 86 \%; m.p. 195-197 ${ }^{\circ} \mathrm{C}$; IR (KBr, cm$\left.{ }^{-1}\right)$ : 3152, 3095, 3064, 2939, 1669, 1586, 1507, 1485, 1472, 1318, 1293, 938, 853; ${ }^{1} \mathrm{H}$ NMR (400 MHz, DMSO-d 6 ) $\delta / \mathrm{ppm:} 2.38(\mathrm{~s}, 3 \mathrm{H}$, $\left.\mathrm{CH}_{3}\right), 3.67\left(\mathrm{~s}, 3 \mathrm{H}, \mathrm{OCH}_{3}\right), 4.12\left(\mathrm{~s}, 2 \mathrm{H}, \mathrm{CH}_{2}\right), 5.49(\mathrm{~s}, 2 \mathrm{H}, \mathrm{N}-$ $\left.\mathrm{CH}_{2}\right), 6.85-6.92(\mathrm{~m}, 2 \mathrm{H}, \mathrm{ArH}), 7.04-7.06(\mathrm{~m}, 1 \mathrm{H}, \mathrm{ArH}), 7.21-$ $7.30(\mathrm{~m}, 2 \mathrm{H}, \mathrm{ArH}), 7.45(\mathrm{~d}, J=8.8 \mathrm{~Hz}, 1 \mathrm{H}, \mathrm{ArH}), 7.73(\mathrm{~s}, 1 \mathrm{H}$, ArH), 7.79-7.85 (m, 2H, ArH), 8.04 (d, J = 4.0 Hz, 1H, ArH), $8.20(\mathrm{~s}, 1 \mathrm{H}, \mathrm{N}=\mathrm{CH}), 11.05(\mathrm{~s}, 1 \mathrm{H}, \mathrm{NH}), 11.32(\mathrm{~s}, 1 \mathrm{H}, \mathrm{CONH})$; ESI-MS: $m$ / z $488.33(\mathrm{M}+1)$.

N'-((1-(4-Bromobenzyl)-5-methoxy-1H-indol-3-yl)methylene)-2-(2-methyl-1H-pyrrolo[2,3-b] pyridin-3yl)acetohydrazide $(9 \mathrm{~g})$

Yield 87 \%; m.p. $215-217{ }^{\circ} \mathrm{C}$; IR $\left(\mathrm{KBr}, \mathrm{cm}^{-1}\right)$ : 3154, 3059, 2935, 1664, 1587, 1539, 1456, 1436, 1165, 1138, 1071, 765; ${ }^{1} \mathrm{H}$ NMR (400 MHz, DMSO-d 6 ) $\delta / \mathrm{ppm}: 2.37\left(\mathrm{~s}, 3 \mathrm{H}, \mathrm{CH}_{3}\right)$, $3.56\left(\mathrm{~s}, 3 \mathrm{H}, \mathrm{OCH}_{3}\right), 4.09\left(\mathrm{~s}, 2 \mathrm{H}, \mathrm{CH}_{2}\right), 5.40\left(\mathrm{~s}, 2 \mathrm{H}, \mathrm{N}-\mathrm{CH}_{2}\right)$, 6.82-6.89 (m, 2H, ArH), 7.16-7.20 (m, 2H, ArH), 7.40 (d, J = $8.8 \mathrm{~Hz}, 1 \mathrm{H}, \mathrm{ArH}), 7.50-7.53(\mathrm{~m}, 2 \mathrm{H}, \mathrm{ArH}), 7.79(\mathrm{~s}, 1 \mathrm{H}, \mathrm{ArH})$, 7.89-7.93 (m, 2H, ArH) $8.04(\mathrm{~d}, J=4.0 \mathrm{~Hz}, 1 \mathrm{H}, \mathrm{ArH}), 8.22(\mathrm{~s}$, $1 \mathrm{H}, \mathrm{N}=\mathrm{CH}) 11.05$ (s, 1H, NH), 11.32 (s, 1H, CONH); ESI-MS: $m / z 530.25(\mathrm{M}+)\left({ }^{79} \mathrm{Br}\right)$. 
$N^{\prime}-((5-B r o m o)-1-(2,4-d i c h l o r o b e n z y l)-1 H-i n d o l-3-y l)-$ methylene)-2-(2-methyl-1H-pyrrolo[2,3-b]pyridin-3yl)acetohydrazide (9h)

Yield 82 \%; m.p. $215-217{ }^{\circ} \mathrm{C}$; IR $\left(\mathrm{KBr}, \mathrm{cm}^{-1}\right): 3153,3062$, 2938, 1669, 1587, 1560, 1473, 1443, 1202, 1101, 936, 858, 702; ${ }^{1} \mathrm{H}$ NMR (400 MHz, DMSO-d 6 ) $\delta / \mathrm{ppm}: 2.35(\mathrm{~s}, 3 \mathrm{H}$, $\left.\mathrm{CH}_{3}\right), 4.06\left(\mathrm{~s}, 2 \mathrm{H}, \mathrm{CH}_{2}\right), 5.43\left(\mathrm{~s}, 2 \mathrm{H}, \mathrm{N}-\mathrm{CH}_{2}\right), 6.82-6.88(\mathrm{~m}$, $2 \mathrm{H}, \mathrm{ArH}), 7.04-7.06(\mathrm{~m}, 1 \mathrm{H}, \mathrm{ArH}), 7.20-7.32(\mathrm{~m}, 2 \mathrm{H}, \mathrm{ArH})$, $7.43(\mathrm{~d}, J=8.8 \mathrm{~Hz}, 1 \mathrm{H}, \mathrm{ArH}), 7.70(\mathrm{~s}, 1 \mathrm{H}, \mathrm{ArH}), 7.74-7.80(\mathrm{~m}$, $2 \mathrm{H}, \mathrm{ArH}), 8.06(\mathrm{~d}, J=4.0 \mathrm{~Hz}, 1 \mathrm{H}, \mathrm{ArH}), 8.22(\mathrm{~s}, 1 \mathrm{H}, \mathrm{N}=\mathrm{CH})$, 11.07 (s, 1H, NH), 11.36 (s, 1H, CONH); ESI-MS: $m$ / z 568.15 $(\mathrm{M}+)\left({ }^{79} \mathrm{Br}\right)$.

\section{$N^{\prime}$-((5-Bromo)-1-(2,4-difluorobenzyl)-1H-indol-3-yl)- methylene)-2-(2-methyl-1H-pyrrolo[2,3-b]pyridin-3- yl)acetohydrazide (9i)}

Yield 88 \%; m.p. $195-197{ }^{\circ} \mathrm{C}$; IR $\left(\mathrm{KBr}, \mathrm{cm}^{-1}\right)$ : 3156, 3065, 2945, 1667, 1589, 1558, 1445, 1407, 1259, 1141, 973, 880, 670; ${ }^{1} \mathrm{H}$ NMR (400 MHz, DMSO-d 6 ) $\delta / \mathrm{ppm}: 2.39$ (s, 3H, $\left.\mathrm{CH}_{3}\right), 4.12\left(\mathrm{~s}, 2 \mathrm{H}, \mathrm{CH}_{2}\right), 5.49\left(\mathrm{~s}, 2 \mathrm{H}, \mathrm{N}-\mathrm{CH}_{2}\right), 6.85-6.92(\mathrm{~m}$, $2 \mathrm{H}, \mathrm{ArH}), 7.04-7.06(\mathrm{~m}, 1 \mathrm{H}, \mathrm{ArH}), 7.21-7.30(\mathrm{~m}, 2 \mathrm{H}, \mathrm{ArH})$, $7.45(\mathrm{~d}, J=8.8 \mathrm{~Hz}, 1 \mathrm{H}, \mathrm{ArH}), 7.73(\mathrm{~s}, 1 \mathrm{H}, \mathrm{ArH}), 7.79-7.85(\mathrm{~m}$, $2 \mathrm{H}, \mathrm{ArH}), 8.04(\mathrm{~d}, J=4.0 \mathrm{~Hz}, 1 \mathrm{H}, \mathrm{ArH}), 8.20(\mathrm{~s}, 1 \mathrm{H}, \mathrm{N}=\mathrm{CH})$, 11.05 (s, 1H, NH), 11.32 (s, 1H, CONH); ESI-MS: $m$ / z 536.19 $(\mathrm{M}+)\left({ }^{79} \mathrm{Br}\right)$.

\section{$N^{\prime}-((5-B r o m o)-1-(4-c y a n o b e n z y l)-1 H-i n d o l-3-y l)-$} methylene)-2-(2-methyl-1H-pyrrolo[2,3-b] pyridin-3yl)acetohydrazide $(9 \mathrm{j})$

Yield 84 \%; m.p. $216-218{ }^{\circ} \mathrm{C}$; IR $\left(\mathrm{KBr}, \mathrm{cm}^{-1}\right)$ : 3154, 3063, 2936, 2842, 2228, 1667, 1609, 1541, 1461, 1389, 1258, $1167,1113,880,787,660 ;{ }^{1} \mathrm{H}$ NMR (400 MHz, DMSO-d 6 ) $\delta$ / ppm: $2.40\left(\mathrm{~s}, 3 \mathrm{H}, \mathrm{CH}_{3}\right), 4.06\left(\mathrm{~s}, 2 \mathrm{H}, \mathrm{CH}_{2}\right), 5.58(\mathrm{~s}, 2 \mathrm{H}, \mathrm{N}-$ $\left.\mathrm{CH}_{2}\right), 6.91-6.98(\mathrm{~m}, 1 \mathrm{H}, \mathrm{ArH}), 7.32-7.36(\mathrm{~m}, 3 \mathrm{H}, \mathrm{ArH}), 7.81-$ $7.86(\mathrm{~m}, 4 \mathrm{H}, \mathrm{ArH}), 8.03-8.06(\mathrm{~m}, 2 \mathrm{H}, \mathrm{ArH}), 8.21(\mathrm{~s}, 1 \mathrm{H}$, $\mathrm{N}=\mathrm{CH}), 8.36-8.41(\mathrm{~m}, 1 \mathrm{H}, \mathrm{ArH}), 11.13(\mathrm{~s}, 1 \mathrm{H}, \mathrm{NH}), 11.34(\mathrm{~s}$, $1 \mathrm{H}, \mathrm{CONH})$; ESI-MS: $m$ / z $525.24(\mathrm{M}+)\left({ }^{79} \mathrm{Br}\right)$.

\section{Anticancer Activity PROCEDURE OF THE SRB-ASSAY}

Anticancer evaluation was performed as per the procedure reported in literature. ${ }^{[9]}$ Tumor cells (human breast cancer cell line MCF-7) were grown in tissue culture flasks in growth medium (RPMI-1640 with $2 \mathrm{mM}$ glutamine, $\mathrm{pH} 7.4$, $10 \%$ fetal calf serum, $100 \mu \mathrm{g} / \mathrm{mL}$ streptomycin, and 100 units / $\mathrm{mL}$ penicillin) at $37{ }^{\circ} \mathrm{C}$ under the atmosphere of $5 \%$ $\mathrm{CO}_{2}$ and $95 \%$ relative humidity employing a $\mathrm{CO}_{2}$ incubator. The cells at subconfluent stage were harvested from the flask by treatment with trypsin $0.05 \%$ trypsin in PBS containing $0.02 \%$ EDTA) and placed in growth medium. The cells with more than $97 \%$ viability (trypan blue exclusion) were used for cytotoxicity studies. An aliquot of $100 \mu \mathrm{L}$ of cells were transferred to a well of 96-well tissue culture plate. The cells were allowed to grow for one day at $37^{\circ} \mathrm{C}$ in a $\mathrm{CO}_{2}$ incubator as mentioned above. The test materials at different concentrations were then added to the wells and cells were further allowed to grow for another $48 \mathrm{~h}$. Suitable blanks and positive controls were also included. Each test was performed in triplicate. The cell growth was stopped by gently layering of $50 \mu \mathrm{L}$ of $50 \%$ trichloroacetic acid. The plates were incubated at $4{ }^{\circ} \mathrm{C}$ for an hour to fix the cells attached to the bottom of the wells. Liquids of all the wells were gently pipette out and discarded. The plates were washed five times with doubly distilled water to remove TCA, growth medium, etc. and were air-dried. $100 \mu \mathrm{L}$ of SRB solution ( $0.4 \%$ in $1 \%$ acetic acid) was added to each well and the plates were incubated at ambient temperature for half an hour. The unbound SRB was quickly removed by washing the wells five times with $1 \%$ acetic acid. Plates were air dried, tris-buffer $(100 \mu \mathrm{L}$ of $0.01 \mathrm{M}, \mathrm{pH} 10.4)$ was added to all the wells and plates were gently stirred for $5 \mathrm{~min}$ on a mechanical stirrer. The optical density was measured on ELISA reader at $540 \mathrm{~nm}$. The cell growth at absence of any test material was considered $100 \%$ and in turn growth inhibition was calculated. Percent growth calculated on a plate-by-plate basis for test wells relative to control wells. Percent growth expressed as the ratio of average absorbance of the test well to the average absorbance of the control wells 100 . Using the six absorbance measurements (time zero, control growth [C] and test growth in the presence of drug at the four concentration levels [Ti]), the percentage growth calculated at each of the extracts and standard drug concentration levels. Percentage growth inhibition calculated as $[\mathrm{Ti} / \mathrm{C}] \times 100 \%$.

\section{RESULTS AND DISCUSSION}

\section{Chemistry}

Synthesis of the 2-methyl-7-azaindolyl hydrazide $\mathbf{5}$ has been accomplished by the chemical reactions outlined in Scheme 1. Mannich reaction of 2-methyl-7-azaindole with $\mathrm{N}, \mathrm{N}$-dimethyl amine hydrochloride and paraformaldehyde gave $\mathrm{N}, \mathrm{N}$-dimethyl-1-(2-methyl-1H-pyrrolo[2,3-b] pyridin$3-y l) m e t h a n a m i n e ~ 1$ which on treatment with methyl iodide in alcohol followed by substitution with sodium cyanide in DMF furnished 2-methyl-7-azaindole-3-acetonitrile 2. The acid hydrolysis of $\mathbf{2}$ gave 2-(2-methyl-1H-pyrrolo[2,3b]pyridin-3-yl)acetic acid 3 which on esterification with methanol and catalytic amount of concentrated $\mathrm{H}_{2} \mathrm{SO}_{4}$, gave corresponding ester $\mathbf{4}$. Methyl ester 4 on treatment with hydrazine hydrate in methanol offered 2-methyl-7azaindolyl hydrazide 5 in excellent yield (Scheme 1).

The 2-methyl-7-azaindolyl hydrazide $\mathbf{5}$ initially reacted with various substituted aromatic aldehydes $6 a-1$ in ethanol at room temperature and later with 


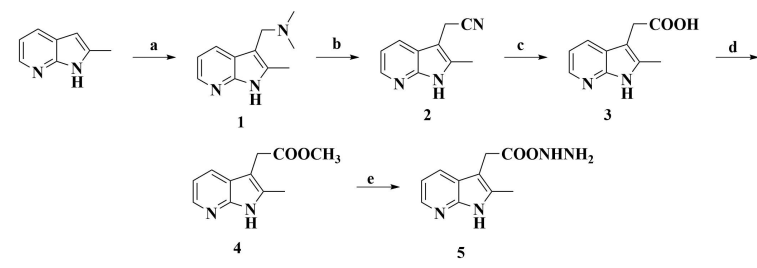

Scheme 1. Synthesis of 2-methyl-7-azaindolyl hydrazide; Reagents and conditions: a) $\mathrm{HN}\left(\mathrm{CH}_{3}\right)_{2} . \mathrm{HCl}, \mathrm{HCHO}, \mathrm{MeOH}$; b) $\mathrm{EtOH}, \mathrm{CH}_{3} \mathrm{l}, \mathrm{NaCN}, \mathrm{DMF}$; c) Aq. $\mathrm{HCl}$, d) $\mathrm{MeOH}, \mathrm{H}_{2} \mathrm{SO}_{4}$; e) $\mathrm{NH}_{2} \mathrm{NH}_{2} \cdot \mathrm{H}_{2} \mathrm{O}$.
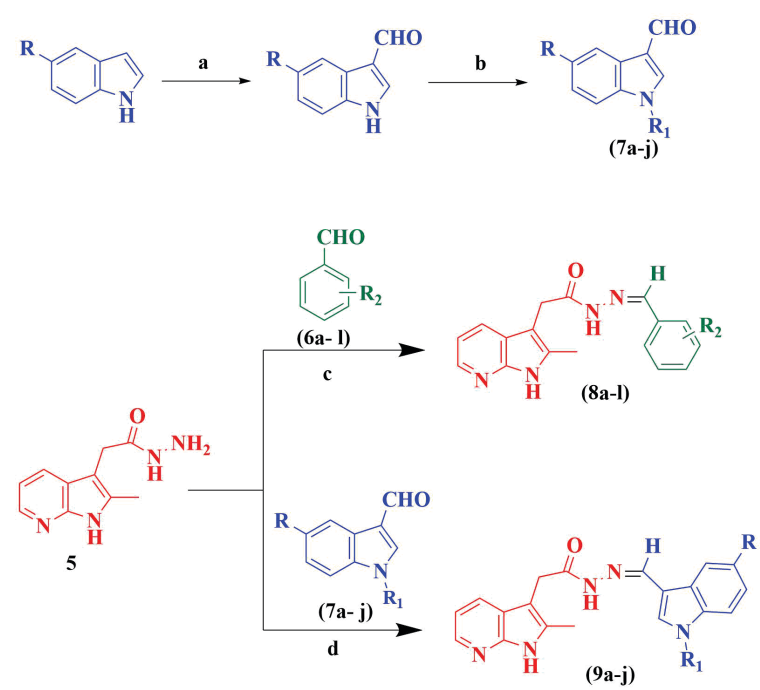

Scheme 2. Synthesis of 7-azaindolyl hydrazones; Reagents and conditions: a) DMF, $\mathrm{POCl}_{3}$; b) NaH, Dry THF $0{ }^{\circ} \mathrm{C}-\mathrm{RT}$;

c) $\mathrm{EtOH}$, glacial $\mathrm{AcOH}$; d) EtOH, glacial $\mathrm{AcOH}$, Reflux.

$\mathrm{N}$-1-substituted indole-3-carboxyaldehydes $7 \mathrm{a}-\mathrm{j}$ in ethanol at reflux for 3-5 $\mathrm{h}$ in the presence of catalytic amount of acetic acid resulted in the formation of hydrazones $8 \mathrm{a}-\mathbf{I}$ and $9 a-\mathbf{j}$, respectively. The various $\mathrm{N}$-1-substituted-indole3-carboxyaldehydes $7 \mathbf{a}-\mathbf{j}$ selected as starting material were prepared by the Vilsmeier-Hack formylation of 5 -substituted indoles followed by $\mathrm{N}$-protection with various substituted alkyl halides in presence of sodium hydride in THF as reaction medium (Scheme 2). The structures of all the synthesized compounds $\mathbf{8} \mathbf{a}-\mathbf{I}$ and $\mathbf{9 a} \mathbf{a} \mathbf{j}$ were established by ${ }^{1} \mathrm{H}$ NMR, IR and mass spectroscopy techniques.

\section{Spectroscopy Study}

It is previously well documented that $\mathrm{N}$-acylhydrazones may exist as geometrical isomers ( $E / Z)$ with respect to the imine bonds and as conformational (cis/trans) isomers around the amide $\mathrm{N}-\mathrm{C}(\mathrm{O})$ bond. ${ }^{[12]}$ In ${ }^{1} \mathrm{H}$ NMR spectrum of compound 8a, we observed two signals for imine protons $(\mathrm{N}=\mathrm{CH}),-\mathrm{CH}_{2}-\mathrm{C}(\mathrm{O})$ and some of the benzylidene protons, which is believed to be due to its existence as conformational
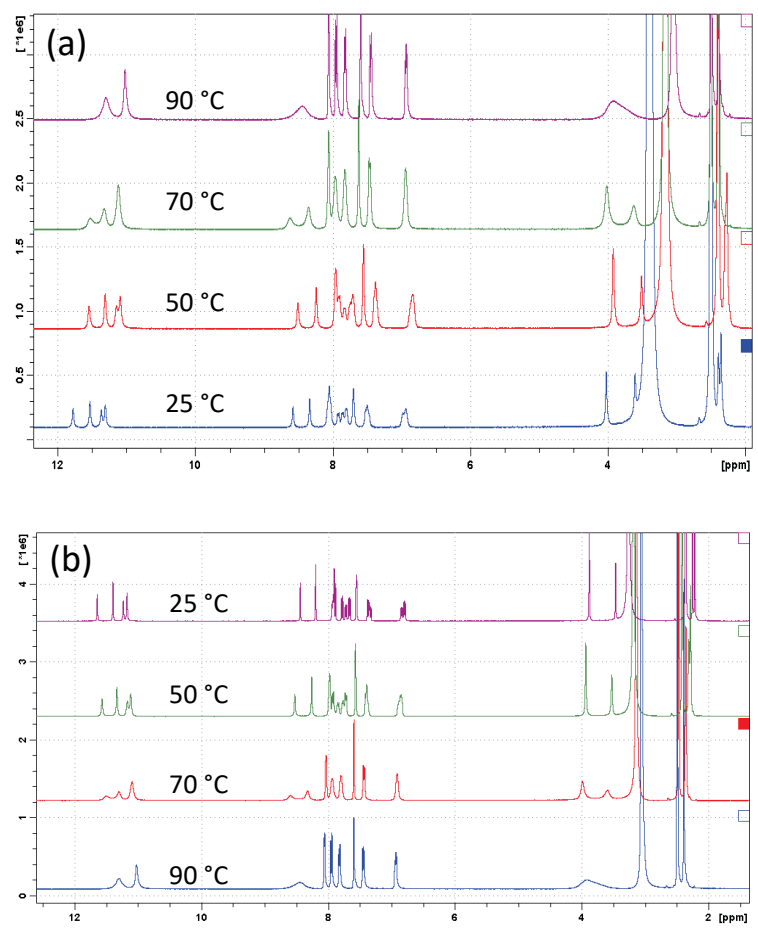

Figure 2. Effect of temperature on isomerization: (a) heating; (b) cooling.

isomers (rotation around $\mathrm{N}-\mathrm{C}(\mathrm{O})$ ) or geometrical isomers $(E / Z, N=\mathrm{CH}) .{ }^{13} \mathrm{C}$ NMR spectrum of compound $8 \mathrm{a}$ also showed two sets of signals for most of its carbon nuclei. In ${ }^{1} \mathrm{H}$ NMR spectra of compound $8 \mathrm{a}$, we observed a mixture of $\mathrm{cis} /$ trans isomers in unequal proportions in solution phase at room temperature. Thus, we studied the possibility of isomerization in solution phase by analyzing sample at various temperatures while heating and cooling. The temperature study revealed that with the rise in temperature up to $90{ }^{\circ} \mathrm{C}$ only one isomer exists predominantly but at $50{ }^{\circ} \mathrm{C}$ and $70^{\circ} \mathrm{C}$, mixture of isomers observed and similarly during cooling conversion of single isomer to mixture of isomers was observed (Figure 2).

\section{BIOLOGICAL EVALUATION}

\section{In vitro Anticancer Activity}

The in vitro anti-proliferative activity of the synthesized compounds was evaluated against human breast cancer cell line MCF-7 and normal Vero monkey cell line by employing sulforhodamine B (SRB) protein assay method. ${ }^{[13]}$ Adriamycin a potent anticancer drug was used as reference standard. The anticancer activity of tested compounds is given by three parameters, $\mathrm{Gl}_{50}$ (molar concentration of the compound that inhibits $50 \%$ net cell growth), TGI (molar concentration of the compound leading to total inhibition) and $\mathrm{LC}_{50}$ (molar concentration of the compound leading to 
$50 \%$ net cell death) and the results are summarized in Table 1. From the results obtained (Table 1), it is clear that all the hydrazones reduce the cancer cell viability significantly with $\mathrm{GI}_{50}$ values ranging from $22.3-81.0 \mu \mathrm{M}$. SRB assay reveals that most of the hydrazones of $\mathrm{N}$-1-substituted indole-3-carboxyaldehydes $\mathbf{9 f}, \mathbf{9 g}, \mathbf{9 h}, \mathbf{9 c}$, and $\mathbf{9 j}$ are potent against MCF-7 cell line with $\mathrm{Gl}_{50}$ values less than $40 \mu \mathrm{M}$ Remaining compounds have shown moderate to weak cytotoxicity against MCF-7 cell line ranging from 58.5$81 \mu \mathrm{M}$.

A comparison of the TGI concentrations of the compounds with adriamycin was also done. Most of the compounds were inactive and a few displayed weak activity against the MCF-7 cell line. Compounds $9 \mathbf{9 f} \mathbf{9 g}, \mathbf{9 h}, \mathbf{9 c}$ and 9j exhibited weak activity (TGI = 56.6, 59.5, 65.5, 70.7, and
94.6 $\mu \mathrm{M}$ respectively) against MCF-7 cell line. All the other compounds found inactive (TGI $>100 \mu \mathrm{M}$ ) as compared to standard drug adriamycin $(\mathrm{TGI}=25.9 \mu \mathrm{M})$.

The $L C_{50}$ concentrations of the compounds were also compared to that of adriamycin to get a sign of the cytotoxic effects of these compounds against the MCF-7 cell line. Most of the compounds were found to be inactive $\left(\mathrm{LC}_{50}>100 \mu \mathrm{M}\right)$ except compound $9 \mathrm{f}$ and $9 \mathrm{~g}$ as like adriamycin $\left(\mathrm{LC}_{50}=92.8 \mu \mathrm{M}\right)$ against the MCF-7 cell line.

Most of the marketed drugs affect the normal cell growth, which serves to be a major disadvantage in the evolution of anticancer drug development. Therefore, we have ensured the selectivity of active compounds by in vitro screening against the normal Vero Monkey cell line (Table 1). These results demonstrate that the synthesized

Table 1. Anticancer activity profile of synthesized hydrazone derivatives against MCF-7 breast cancer cell line.

\begin{tabular}{|c|c|c|c|c|c|c|c|c|c|}
\hline \multirow{2}{*}{ Entry } & \multicolumn{3}{|c|}{ Substitutions } & \multicolumn{3}{|c|}{ MCF-7 } & \multicolumn{3}{|c|}{ Vero (Normal) } \\
\hline & $R$ & $\mathrm{R}_{1}$ & $\mathrm{R}_{2}$ & $\mathrm{Gl}_{50}^{(\mathrm{a})}$ & $\mathrm{LC}_{50}^{(\mathrm{b})}$ & $\mathrm{TG}^{(\mathrm{c})}$ & $\mathrm{Gl}_{50}^{(\mathrm{a})}$ & $\mathrm{LC}_{50}{ }^{(\mathrm{b})}$ & $\mathrm{TG}^{(\mathrm{c})}$ \\
\hline $8 a$ & - & - & $2,4-(\mathrm{Cl})_{2} \mathrm{C}_{6} \mathrm{H}_{3}$ & 75.0 & $>100$ & $>100$ & NT & NT & NT \\
\hline $8 b$ & - & - & $3,4-(\mathrm{F})_{2} \mathrm{C}_{6} \mathrm{H}_{3}$ & 73.5 & $>100$ & $>100$ & NT & NT & NT \\
\hline $8 c$ & - & - & $3,4,5-(\mathrm{MeO}){ }_{3} \mathrm{C}_{6} \mathrm{H}_{2}$ & 72.5 & $>100$ & $>100$ & NT & NT & NT \\
\hline $8 d$ & - & - & $3,4-\left(\mathrm{O}-\mathrm{CH}_{2}-\mathrm{O}\right) \mathrm{C}_{6} \mathrm{H}_{3}$ & 69.8 & $>100$ & $>100$ & NT & NT & NT \\
\hline $8 \mathrm{e}$ & - & - & $2,4-(\mathrm{F})_{2} \mathrm{C}_{6} \mathrm{H}_{3}$ & 78.7 & $>100$ & $>100$ & NT & NT & NT \\
\hline $8 f$ & - & - & $3-\mathrm{NO}_{2}-\mathrm{C}_{6} \mathrm{H}_{4}$ & 68.9 & $>100$ & $>100$ & NT & NT & NT \\
\hline $8 g$ & - & - & $2,4,6-(\mathrm{MeO})_{3} \mathrm{C}_{6} \mathrm{H}_{2}$ & 75.2 & $>100$ & $>100$ & NT & NT & NT \\
\hline $8 \mathrm{~h}$ & - & - & $3-\mathrm{Br}-\mathrm{C}_{6} \mathrm{H}_{4}$ & 70.4 & $>100$ & $>100$ & NT & NT & NT \\
\hline $8 \mathrm{i}$ & - & - & $4-\mathrm{OH}-\mathrm{C}_{6} \mathrm{H}_{4}$ & 58.5 & $>100$ & $>100$ & NT & NT & NT \\
\hline $8 j$ & - & - & 3-F-4-OMe- $\mathrm{C}_{6} \mathrm{H}_{3}$ & 76.2 & $>100$ & $>100$ & NT & NT & NT \\
\hline $8 \mathrm{k}$ & - & - & 3-OMe-4-OH- $\mathrm{C}_{6} \mathrm{H}_{3}$ & 62.6 & $>100$ & $>100$ & NT & NT & NT \\
\hline 81 & - & - & $4-\mathrm{CN}-\mathrm{C}_{6} \mathrm{H}_{4}$ & 60.1 & $>100$ & $>100$ & NT & NT & NT \\
\hline $9 a$ & $\mathrm{H}$ & $4-\mathrm{ClC}_{6} \mathrm{H}_{4} \mathrm{CH}_{2}$ & - & 72.1 & $>100$ & $>100$ & NT & NT & NT \\
\hline $9 b$ & $\mathrm{H}$ & $4-\mathrm{FC}_{6} \mathrm{H}_{4} \mathrm{CH}_{2}$ & - & 80.2 & $>100$ & $>100$ & NT & NT & NT \\
\hline $9 c$ & $\mathrm{H}$ & $2,4-(\mathrm{Cl})_{2} \mathrm{C}_{6} \mathrm{H}_{3} \mathrm{CH}_{2}$ & - & 30.2 & $>100$ & 70.7 & 59.4 & $>100$ & $>100$ \\
\hline $9 d$ & $\mathrm{H}$ & $2,4-(\mathrm{F})_{2} \mathrm{C}_{6} \mathrm{H}_{3} \mathrm{CH}_{2}$ & - & 77.8 & $>100$ & $>100$ & NT & NT & NT \\
\hline $9 e$ & 5-OMe & $2,4-(\mathrm{Cl})_{2} \mathrm{C}_{6} \mathrm{H}_{3} \mathrm{CH}_{2}$ & - & 73.2 & $>100$ & $>100$ & NT & NT & NT \\
\hline $9 f$ & 5-OMe & $2,4-(\mathrm{F})_{2} \mathrm{C}_{6} \mathrm{H}_{3} \mathrm{CH}_{2}$ & - & 22.3 & 90.3 & 56.6 & 23.8 & 75.9 & 68.2 \\
\hline $9 g$ & 5-OMe & 4- $\mathrm{BrC}_{6} \mathrm{H}_{4} \mathrm{CH}_{2}$ & - & 24.9 & 94.0 & 59.5 & 18.2 & 86.8 & 45.5 \\
\hline $9 \mathrm{~h}$ & $5-\mathrm{Br}$ & $2,4-(\mathrm{Cl})_{2} \mathrm{C}_{6} \mathrm{H}_{3} \mathrm{CH}_{2}$ & - & 29.6 & $>100$ & 65.5 & 25.1 & 99.4 & 52.3 \\
\hline $9 i$ & $5-\mathrm{Br}$ & $2,4-(\mathrm{F})_{2} \mathrm{C}_{6} \mathrm{H}_{3} \mathrm{CH}_{2}$ & - & 81.0 & $>100$ & $>100$ & NT & NT & NT \\
\hline $9 j$ & $5-B r$ & $4-\mathrm{CNC}_{6} \mathrm{H}_{4} \mathrm{CH}_{2}$ & - & 37.8 & $>100$ & 94.6 & 22.5 & $>100$ & 77.6 \\
\hline ADR & - & - & - & $<0.1$ & 92.8 & 25.9 & 19 & 52.5 & $>10$ \\
\hline
\end{tabular}

(a) Concentrations in $\mu \mathrm{M}$; Growth inhibition of $\left.50 \%(G)_{50}\right)$ calculated from $[(T i-T z) /(C-T z)] \times 100=50$.

(b) Concentration of drug resulting in a $50 \%$ reduction in the measured protein at the end of the drug treatment as compared to that at the beginning) calculated from $[(T i-T z) / T z] \times 100=-50$.

(c) Drug concentration resulting in total growth inhibition (TGI) will calculated from $T i=T z$.

$\mathrm{ADR}=$ adriamycin 
7-azaindolyl hydrazine derivatives $\mathbf{9 f}, \mathbf{9 g}, \mathbf{9 h}, \mathbf{9 c}$, and $\mathbf{9 j}$ show moderate selectivity against cancer lines over normal cell line.

\section{CONCLUSION}

In conclusion, a series of 7-azaindolyl hydrazones were prepared and their structures were analyzed by FT-IR, ${ }^{1} \mathrm{H}$ NMR and mass spectral data. All the compounds were screened for their anticancer potential against MCF-7 induced breast carcinoma. All the compounds screened were found to possess notable anticancer potential. Compounds $\mathbf{9 f}, \mathbf{9 g}, \mathbf{9 h}, \mathbf{9 c}$, and $\mathbf{9 j}$ were significantly active against MCF-7 cell line with $\mathrm{Gl}_{50}$ values ranging from 22.3$37.8 \mu \mathrm{M}$ and TGI values 56.6-94.6 $\mu \mathrm{M}$. Thus, these compounds constitute an interesting template and may be helpful for the design and development of new therapeutic tools against cancer.

Acknowledgment. We offer thanks to ACTREC Mumbai for providing anticancer activity determinations. We also thank Instrumentation Centre, Solapur University for providing facility of spectral analysis.

\section{REFERENCES}

[1] (a) S. Sibu, P. Jan, Plant Science 2011, 180, 454-460. https://doi.org/10.1016/j.plantsci.2010.12.007

(b) S. Wu, L. Wang, W. Guo, X. Liu, J. Liu, X. Wei, B. Fang, J. Med. Chem. 2011, 54, 2668-2679. https://doi.org/10.1021/jm101417n

(c) N. I. Park, J. K. Kim, W. T. Park, J. W. Cho, Y. P. Lim, S. U. Park, Molecular Biology Reports 2010, 38, 4947-4953. https://doi.org/10.1007/s11033-010-0638-5

[2] R. Singla, V. Singh, A. Negi, Adv. J. Pharma Life. Sci. Res. 2013, 1, 7-15.

[3] (a) A. Carbone, M. Pennati, B. Parrino, A. Lopergolo, P. Barraja, A. Montalbano, V. Spanò, S. Sbarra, V. Doldi, M. De Cesare, G. Cirrincione, P. Diana, N. Zaffaroni, J. Med. Chem. 2013, 56, 7060-7072. https://doi.org/10.1021/jm400842x (b) H. R. Bokesch, L. K. Pannell, T. C. McKeea, M. R. Boyd, Tetrahedron Letters 2000, 41, 6305-6308. https://doi.org/10.1016/S0040-4039(00)01062-5 (c) A. Wienecke, G. Bacher, Cancer Res. 2009, 69, 171177. https://doi.org/10.1158/0008-5472.CAN-08-1342.

(d) H .R. Pettit, J. C. Knight, D. L. Herald, R. Davenport, R. K. Pettit, B. E. Tucker, J. M. Schmidt, J. Nat. Prod. 2002, 65, 1793-1797. https://doi.org/10.1021/np020173x (e) G. Wylie, T. Appelboom, W. Bolten, F. C. Breedveld, J. Feely, M. R. Leeming, X. Le Loët, R. Manthorpe, R. Marcolongo, J. Smolen, British Journal of Rheumatology 1995, 34, 554-563. https://doi.org/10.1093/rheumatology/34.6.554
[4] (a) J-Y. Merour, S. Routier, F. Suzenet, B. Joseph, Tetrahedron 2013, 69, 4767.

https://doi.org/10.1016/j.tet.2013.03.081

(b) F. Popowycz, S. Routier, B. Josepha, J-Y. Merour, Tetrahedron 2007, 63, 1031-1064.

https://doi.org/10.1016/j.tet.2006.09.067

[5] (a) W. Zhu, C. Chen, C. Sun, S. Xu, C. Wu, F. Lei, H. Xia, Q. Tu, P. Zheng, Eur. J. Med. Chem. 2015, 93, 6473. https://doi.org/10.1016/j.ejmech.2015.01.061

(b) R. G. Strachan, M. A. P. Meisinger, W. V. Ruyle, R. Hirschmann, T. Y. Shen, J. Med. Chem. 1964, 7, 799800. https://doi.org/10.1021/jm00336a026

(c) D. Kumar, N. M. Kumar, S. Ghosh, K. Shah, Bioorg. Med. Chem. Lett. 2012, 22, 212-215.

https://doi.org/10.1016/j.bmcl.2011.11.031

(d) S. Schmidt, L. Preu, T. Lemcke, F. Totzke, C. Schächtele, M. H. G. Kubbutat, C. Kunick, Eur. J. Med. Chem. 2011, 46, 2759-2769.

https://doi.org/10.1016/j.ejmech.2011.03.065

(e) O. Ünsal-Tana, K. Özdenc, A. Raukb, A. Balkana, Eur. J. Med. Chem. 2010, 45, 2345-2352.

https://doi.org/10.1016/j.ejmech.2010.02.012

[6] (a) S. Hong, J. Kim, J. Hyeon Seo, K. Hee Jung, S.-S. Hong, S. Hong, J. Med. Chem. 2012, 55, 5337-5349. https://doi.org/10.1021/jm3002982

(b) H.-R. Tsou, G. MacEwan, G. Birnberg, N. Zhang, N. Brooijmans, L. Toral-Barza, I. Hollander, S. AyralKaloustian, K. Yu, Bioorg. Med. Chem. Lett. 2010, 20, 2259-2263.

https://doi.org/10.1016/j.bmcl.2010.02.012

(c) D. Simard, Y. Leblanc, C. Berthelette, M.H. Zaghdane, C. Molinaro, Z. Wang, M. Gallant, S. Lau, T. Thao, M. Hamel, R. Stocco, N. Sawyer, S. Sillaots, F. Gervais, R. Houle, J.-F. Levesque, Bioorg. Med. Chem. Lett. 2011, 21, 841-845.

https://doi.org/10.1016/j.bmcl.2010.11.084

(d) M. Kritsanida, P. Magiatis, A.-L. Skaltsounis, Y. Peng, P. Li, L. P. Wennogle, J. Nat. Prod. 2009, 72, 2199-2202. https://doi.org/10.1021/np9003905

(e) J.-Y. Merour, F. Buron, K. Ple, P. Bonnet, S. Routier, Molecules 2014, 19, 19935-19979.

https://doi.org/10.3390/molecules191219935

(f) J. F. Kadow, Y. Ueda, N. A. Meanwell, T. P. Connolly, T. Wang, C.-P. Chen, K.-S. Yeung, J. Zhu, J. A. Bender, Z. Yang, D. Parker, P.-F. Lin, R. J. Colonno, M. Mathew, D. Morgan, M. Zheng, C. Chien, D. Grasela, J. Med. Chem. 2012, 55, 2048-2056. https://doi.org/10.1021/jm201218m

[7] S. Rollas, S. Guniz Kucukguzel, Molecules 2007, 12, 1910-1939. https://doi.org/10.3390/12081910

[8] (a) S. G. Küçükgüzel, A. Mazi, F. Sahin, S. Öztürk, J. Stables, Eur. J. Med. Chem. 2002, 38, 1005-1013. https://doi.org/10.1016/j.ejmech.2003.08.004 
(b) S. M. Sondhi, M. Dinodia, A. Kumar, Bioorg. Med. Chem. 2006, 14, 4657-4663.

https://doi.org/10.1016/j.bmc.2006.02.014

(c) Z. Garkani-Nejad, B. Ahmadi-Roudi, Eur. J. Med. Chem. 2010, 45, 719-726.

https://doi.org/10.1016/j.ejmech.2009.11.019

(d) L. Savini, L. Chiasserini, A. Gaeta, C. Pellerano, Bioorg. Med. Chem. 2002, 10, 2193-2198.

https://doi.org/10.1016/S0968-0896(02)00071-8

(e) P. Vicini, M. Incerti, I. A. Doytchinova, P. La Colla, B. Busonera, R. Loddo, Eur. J. Med. Chem. 2006, 41, 624632. https://doi.org/10.1016/j.ejmech.2006.01.010

(f) N. Terzioglu, A. Gürsoy, Eur. J. Med. Chem. 2003 38, 781; (g) A. H. Abadi, A. A. H. Eissa, G. S. Hassan, Chem. Pharm. Bull. 2003, 51, 838-844.

https://doi.org/10.1248/cpb.51.838

[9] (a) J.-M. Lehn, Chem. Soc. Rev. 2007, 36, 151-160. https://doi.org/10.1039/B616752G

(b) F. J. Uribe-Romo, C. J. Doonan, H. Furukawa, K. Oisaki, and O. M. Yaghi, J. Am. Chem. Soc. 2011, 133, 11478-11481. https://doi.org/10.1021/ja204728y

(c) Y. Jin, C. Yu, R. J. Denman, W. Zhang, Chem. Soc. Rev. 2013, 42, 6634-6654.

https://doi.org/10.1039/c3cs60044k

[10] (a) V. H. Masand, D. T. Mahajan, T. B. Hadda, R. D. Jawarkar, H. Chavan, B. P. Bandgar, H. Chauhan, Med. Chem. Res. 2014, 23, 417-425.

https://doi.org/10.1007/s00044-013-0647-8

(b) B. P. Bandgar, S. A. Patil, J. V. Totre, B. L. Korbad, R. N. Gacche, B. S. Hote, S. S. Jalde, H. V. Chavan, Bioorg. Med. Chem. Lett. 2010, 20, 2292-2296. https://doi.org/10.1016/j.bmcl.2010.02.001

(c) B. P. Bandgar, L. K. Adsul, S. V. Lonikar, H. V. Chavan, S. N. Shringare, S. A: Patil, S. S. Jalde, B. A. Koti, N. A. Dhole, R. N. Gacche, A. Shirfule, J. Enz. Inhib. Med. Chem. 2013, 28, 593-600. https://doi.org/10.3109/14756366.2012.663365 (d) B. P. Bandgar, S. S. Jalde, B. L. Korbad, S. A. Patil, H. V. Chavan, S. N. Kinkar, L. K. Adsul, S. N. Shringare, S. H. Nile, J. Enz. Inhib. Med. Chem. 2012, 27, 267-274. https://doi.org/10.3109/14756366.2011.587416

(e) H. V. Chavan, L. K. Adsul, A. S. Kotmale, V. D. Dhakane, V. N. Thakare, B. P. Bandgar, J. Enz. Inhib. Med. Chem. 2015, 30, 22-31.

https://doi.org/10.3109/14756366.2013.873037

(f) B. P. Bandgar, R. J. Sarangdhar, F. Khan, J. Mookkan, S. Chaudhary, H. V. Chavan, S. B. Bandgar, V. Y. Kshirsagar, Eur. J. Med. Chem. 2012, 57, 217-224. https://doi.org/10.1016/j.ejmech.2012.08.036

(g) P. S. Bhale, H. V. Chavan, S. B. Dongare, S. N. Shringare, Y. B. Mule, S. S. Nagane, B. P. Bandgar, Bioorg. Med. Chem. Lett. 2017, 27, 1502-1507. https://doi.org/10.1016/j.bmcl.2017.02.052

[11] D. A. Sandham, C. Adcock, K. Bala, L. Barker, Z. Brown, G. Dubois, D. Budd, B. Cox, R. A. Fairhurst, M. Furegati, C. Leblanc, J. Manini, R. Profit, J. Reilly, R. Stringer, A. Schmidt, K. L. Turner, S. J. Watson, J. Willis, G. Williams, C. Wilson, Bioorg. Med. Chem. Lett. 2009, 19, 4794-4798. https://doi.org/10.1016/j.bmcl.2009.06.042

[12] (a) M. Zhou, Y.-J. Eun, I. A. Guzei, D. B. Weibel, ACS Med. Chem. Lett. 2013, 4, 880-885.

https://doi.org/10.1021/ml400234x

(b) O. Unsal-Tan, K. Ozden, A. Rauk, A. Balkan, Eur. J. Med. Chem. 2010, 45, 2345-2352.

https://doi.org/10.1016/j.ejmech.2010.02.012

(c) V. V. Syakaev, S. N. Podyachev, B. I. Buzykin, S. K. Latypov, W. D. Habicher, A. I. Konovalov, J. Mol. Struct. 2006, 788, 55-62.

https://doi.org/10.1016/j.molstruc.2005.11.018

[13] P. Skehan, R. Strong, D. Scadiaro, A. Monks, J. McMahon, D. Vistica, J. T. Warren, H. Bokesch, S. Kenney, M. R. Boyed, J. Natl. Cancer Inst. 1990, 82, 1107-1112. https://doi.org/10.1093/jnci/82.13.1107 